\title{
Simulating the chemical kinetics of CO2-methane exchange in hydrate
}

DOI:

10.1016/j.jngse.2018.12.018

\section{Document Version}

Accepted author manuscript

Link to publication record in Manchester Research Explorer

\section{Citation for published version (APA):}

Gharasoo, M., Babaei, M., \& Haeckel, M. (2018). Simulating the chemical kinetics of CO2-methane exchange in hydrate. Journal of Natural Gas Science and Engineering. https://doi.org/10.1016/j.jngse.2018.12.018

\section{Published in:}

Journal of Natural Gas Science and Engineering

\section{Citing this paper}

Please note that where the full-text provided on Manchester Research Explorer is the Author Accepted Manuscript or Proof version this may differ from the final Published version. If citing, it is advised that you check and use the publisher's definitive version.

\section{General rights}

Copyright and moral rights for the publications made accessible in the Research Explorer are retained by the authors and/or other copyright owners and it is a condition of accessing publications that users recognise and abide by the legal requirements associated with these rights.

\section{Takedown policy}

If you believe that this document breaches copyright please refer to the University of Manchester's Takedown Procedures [http://man.ac.uk/04Y6Bo] or contact uml.scholarlycommunications@manchester.ac.uk providing relevant details, so we can investigate your claim.

\section{OPEN ACCESS}




\title{
Simulating the chemical kinetics of $\mathrm{CO}_{2}$-methane exchange in hydrate
}

\author{
Mehdi Gharasoo ${ }^{1,2, *}$, Masoud Babaei ${ }^{3}$, and Matthias Haeckel ${ }^{4}$ \\ ${ }^{1}$ Technical University of Munich, Chair of Analytical Chemistry and Water Chemistry, \\ Marchioninistr. 17, 81377 Munich, Germany \\ ${ }^{2}$ Helmholtz Zentrum München, Institute of Groundwater Ecology, Ingolstädter Landstr. \\ 1, 85764 Neuherberg, Germany \\ ${ }^{3}$ University of Manchester, School of Chemical Engineering and Analytical Science, \\ Manchester, M13 9PL, UK \\ ${ }^{4}$ GEOMAR - Helmholtz Centre for Ocean Research, Department of Marine Geosystems, \\ Wischhofstraße 1-3, 24148 Kiel, Germany \\ ${ }^{*}$ Corresponding author. Tel.: +49 893187 3498; E-mail: \\ mehdi.gharasoo@helmholtz-muenchen.de
}

October 27, 2018

\begin{abstract}
Carbon dioxide exchange with methane in the clathrate structure has been shown beneficial in laboratory experiments and has been suggested as a field-scale technique for production of natural gas from gas-hydrate bearing sediments. Furthermore, the method is environmentally attractive due to the formation of $\mathrm{CO}_{2}$-hydrate in the sediments, leading to the geosequestration of carbon dioxide. However, the knowledge is still limited on the impact of small-scale heterogeneities on hydrate dissociation kinetics. In the present study, we developed a model for simulating laboratory experiments of carbon dioxide injection into a pressure vessel containing a mixture of gas hydrate and quartz sand. Four experiments at different temperature and pressure conditions were modeled. The model assumes that the contents are ideally mixed and aims to estimate the effective dissociation rate of gas hydrate by matching the model results with the experimental observations. Simulation results indicate that with a marginal offset the model was able to simulate different hydrate dissociation experiments, in particular, those that are performed at high pressures and low temperatures. At low pressures and high temperatures large discrepancies were noticed between the model results and the experimental observations. The mismatches were attributed to the development of extremely heterogeneous flow patterns at pore-scale, where field-scale models usually assume the characteristics to be uniform. Through this modeling study we estimated the irreversible dissociation rate of methane- and $\mathrm{CO}_{2}$-hydrate as 0.02 and 0.03 mol. $\mathrm{m}^{-3} \mathrm{~s}^{-1}$, respectively.
\end{abstract}

Keywords: $\mathrm{CO}_{2}$ injection; $\mathrm{CO}_{2}$-methane exchange; Gas-hydrate recovery; Small-scale heterogeneities; Kinetic modeling 


\section{Introduction}

Gas-hydrates are solid clathrate compounds that are thermodynamically stable at low temperatures and high pressures. Such conditions naturally exist below permafrost and in deep ocean sediments in which immense amount of methane is estimated to be stored as gas-hydrate deposits (Archer et al., 2009; Burwicz et al., 2011). The global amount of gas-hydrate deposits have been reported between $10^{15}$ and $10^{18}$ standard cubic meters (Pin̄ero et al., 2013; Wallmann et al., 2012), or about 15 Tera tonnes of oil equivalent (Makogon, 2010) which is adequate for maintaining the supply of energy for centuries. Although the range of estimates is wide, it is agreed that the available amount of gas-hydrate deposits is huge and thus worth of the attention as an alternative source of energy. Development of strategies for extraction of methane from gas-hydrate reservoirs has recently become an economically attractive option given the environmental desirability of natural gas as a fuel in comparison to other fossil fuels.

Methods of producing natural gas from gas-hydrates are mainly based on disturbing the thermodynamic stability of gas-hydrate in the reservoir leading to dissociation of the gas-hydrate and release of the methane. The methods include (i) thermal stimulation by increasing the temperature in the reservoir (e.g., Fitzgerald and Castaldi, 2013), (ii) depressurization (e.g., Ahmadi et al., 2007), (iii) hydrate conversion by substituting gas molecules inside the gas-hydrate crystals with another similar gas (e.g., Kvamme et al., 2007, 2016; Ohgaki et al., 1996), and (iv) injection of thermodynamic inhibitors (e.g., amino acids, salts, alcohols or non-ionic surfactants) (Erfani et al., 2017; Masoudi and Tohidi, 2005) for altering phase equilibrium conditions. Amongst all these methods, the conversion of methane-hydrate to $\mathrm{CO}_{2}$-hydrate by injection of $\mathrm{CO}_{2}$ has particularly attracted attentions since carbon dioxide is shown to be able to displace methane in the hydrate lattice provided that both gases form a similar hydrate structure (type SI) (Kvamme et al., 2016; Ohgaki et al., 1996; Voronov et al., 2014). The replacement of guest molecules can happen either directly without dissociation of the hydrate structure or indirectly through consecutive dissociation of methane-hydrate and formation of $\mathrm{CO}_{2}$-hydrate. Goel (2006) discussed that the introduction of carbon dioxide to the reservoir and its conversion to hydrate is alone sufficient to thermodynamically maintain the dissociation of methane-hydrate. The $\mathrm{CO}_{2}$-methane exchange, regardless of its exchange mechanism, is particularly interesting for its capacity to sequester carbon dioxide in favor of reducing greenhouse gas emissions (see e.g., Dashti et al., 2015; Kvamme et al., 2007). The method also has a couple of other side benefits such as main- 
taining the mechanical stability of the reservoir preventing sea-floor landslides in field operations (Sultan et al., 2004), and the potential for thermal stimulation through the injection of supercritical carbon dioxide (Deusner et al., 2012; Ebinuma, 1993). The feasibility of $\mathrm{CO}_{2}$-methane exchange as a technology to produce natural gas from gas-hydrate zones has already been proposed and investigated (e.g., Yonkofski et al., 2016). Many other studies, e.g., Kvamme et al. (2016); Deusner et al. (2012); Ota et al. (2005), analyzed the outcome of $\mathrm{CO}_{2}$-methane exchange at laboratory scale using apparatuses in which carbon dioxide (either gas or liquid) is injected into a vessel containing methane-hydrate. A substantial number of studies have used numerical models to evaluate the conventional methods of production from gas-hydrate reservoirs (e.g., Moridis and Reagan, 2011a,b; Vafaei et al., 2014). However, numerical studies on $\mathrm{CO}_{2}$-methane exchange are few and are mostly limited to the field-scale. For example, White et al. (2011) modeled the injection of carbon dioxide into a depressurized gas-hydrate reservoir and stated that the low injection pressures of carbon dioxide can enhance the methane recovery from class 1 hydrate.

Although significant research efforts have been dedicated to the development of efficient experimental procedures and reliable models[they may ask for references], the complex reaction kinetics of $\mathrm{CO}_{2}$-methane exchange at the scales of pore to core has not yet been addressed in detail or experimentally constrained under the controlled conditions. Most of current modeling approaches [e.g. ???] simplify the reaction kinetics (usually employ a simple first-order kinetics) and neglect the small-scale heterogeneities at the scale of their computational grid (where the transport properties are averaged and considered constant).

In contrast to the existing modeling studies that mostly concentrated on complexity of fluid dynamics at large scales (and simplified the reaction kinetics due to uprising numerical instabilities), the present model focuses on complexity of the reaction kinetics and simplifies the fluid flow mechanisms. To this end, the approach provides a measure to gauge the lone importance of kinetics at small scales where heterogeneities are typically ignored. The overall aim is thus to use the numerical simulations to unravel the extent of influence that typical assumptions of simplifying reaction kinetics and ignoring pore-scale heterogeneities have on the accuracy of estimations at small scales, and to illustrate the contributions of error to field-scale modeling calculations. Are you sure about the word uprising above? Furthermore, the present study evaluates the reported rate values of hydrate dissociation and formation in the 
literature and approximates/testifies the effective rate parameter values for the experimental results of Deusner et al. (2012). For this purpose, a rigorous optimization technique (Babaei and Pan, 2016) was applied to fit the model to the experimental results.

The paper is structured as follows: first we describe the model structure and its underlying assumptions. Then, the governing equations of hydrate dissociation/formation kinetics, mass and energy balance are introduced. Next, we describe the optimization formulation to calibrate the system kinetics using existing experimental data from Deusner et al. (2012). Finally, results are presented and discussed.

\section{Experimental Setup}

Deusner et al. (2012) examined methane production from hydrates by injection of supercritical carbon dioxide into a pressure vessel containing a water-saturated mixture of methane-hydrate and quartz sand. The experiments were performed at four different pressure-temperature conditions that are typical for naturally formed gas-hydrate reservoirs (Fig. 1).

The sediment samples were prepared at $-20{ }^{\circ} \mathrm{C}$ from a homogeneous mixture of quartz sand (grain size of 0.1-0.6 mm) and fine ice particles (grain size fraction of 0.3-1 mm) produced from deionized water. Experiments were carried out in a custom-made high pressure stainless steel apparatus. Supercritical $\mathrm{CO}_{2}$ was injected with a piston pump from an inlet at the bottom of the sample vessel and was heated to $95{ }^{\circ} \mathrm{C}$ inside temperature controlled conditioning chamber prior to the injection. Pressure, salinity and temperature were continuously monitored and recorded at the inlet and outlet. To achieve a constant rate of injection, pressure was adjusted with a back-pressure regulator valve in line with a fine-regulating valve for the compensation of pressure spikes. At the beginning of every $\mathrm{CO}_{2}$ injection interval, the sediment-hydrate sample was continuously percolated with saltwater at a flow rate of $1.0 \mathrm{ml} \cdot \mathrm{min}^{-1}$. The water pre-wash was performed to ensure that the sample body was permeable and homogeneously pressurized. $\mathrm{CO}_{2}$ was injected stepwise following a sequential injection strategy and completed after a four to six injection rounds with $\mathrm{CO}_{2}$ supply rates of 2.5 to $5 \mathrm{ml} . \mathrm{min}^{-1}$. The waiting time between the injection intervals are referred to as equilibration intervals during which no effluent fluid was produced and the system was left to reach thermodynamic equilibrium. During the equilibration intervals, the system pressure was maintained by the injection of a small amount of $\mathrm{CO}_{2}$ in order to compensate the volume changes due to $\mathrm{CO}_{2}$ cooling and phase changes. The $\mathrm{CO}_{2}$ injection 
intervals and the waiting time between them were different for each experiment.

Experiments were performed at three ambient temperatures $\left(2,8\right.$ and $\left.10{ }^{\circ} \mathrm{C}\right)$. The temperature was regulated at the exterior surface of the vessel with a thermostat system and kept constant through the entire experiment. At the start of experiment, the vessel included only three components: methane, water and quartz sand. Methane and water initially existed as methane-hydrate. The quartz sand was assumed nonreactive and regarded as an inert solid phase. During injection intervals, the introduction of hot $\mathrm{CO}_{2}$ altered the system thermodynamics and new additional components such as liquid $\mathrm{CO}_{2}$ and gaseous methane were identified (Fig. 2). $\mathrm{CO}_{2}$-hydrate formation was also viable depending on system $\mathrm{p} / \mathrm{T}$ conditions during equilibration. It was impossible to exactly determine the final composition of gas-hydrate at the end of the experiments. There is, however, a high possibility that a mixed $\mathrm{CO}_{2}-\mathrm{CH}_{4}$-hydrate was formed in the vessel. Nevertheless, the mixed composition of gas-hydrates could not influence the mass balance calculations which were done based on component inventories and by the volume balancing of inputs and outputs. See Deusner et al. (2012) for further details about the experiments and the assembly of apparatus.

\section{Materials and Methods}

The model describes the experimental pressure vessel as an isobaric perfectly mixed reactor. In this modeling approach, the system was considered homogeneous and the chemical components inside it were assumed ideally mixed.

In the model, superheated liquid $\mathrm{CO}_{2}$ entered from the inlet during the injection periods and dissociates the methane-hydrate in place. Then the system is left to reach the equilibrium and this cycle repeats for several times according to the experimental procedure. Given that the vessel pressure was kept constant during the entire experiment, the mobile substances (e.g., water, $\mathrm{CO}_{2}$ and methane) were allowed to discharge from the outlet during the injection intervals only. The outlet composition was assumed identical to the composition of the substances inside the reactor, which itself is a function of residence time and the reaction kinetics. Depending on the $\mathrm{p} / \mathrm{T}$ conditions in the vessel, $\mathrm{CO}_{2^{-}}$or methane-hydrate could form during the equilibrium intervals. The terms $\mathrm{CO}_{2}$-hydrate and methane-hydrate in this modeling study represent the components $\mathrm{CO}_{2}$ and methane incorporated in the gas-hydrate phase. The thermodynamics of mixed gas-hydrates is not explicitly considered in the model. 


\subsection{Governing equations}

\subsubsection{Mass balance}

System mass balance follows the equation (COMSOL 4.3, 2013),

$$
\frac{d\left(c_{j} V_{r}\right)}{d t}=v_{j} c_{i, j}-v_{j} c_{j}+r_{j} V_{r}
$$

where $V_{r}$ is the volume of reactor, $c_{j}$ is the concentration of substance $j$ (Water, $\mathrm{CO}_{2}$, methane, etc.) in the system, $c_{i, j}$ is the concentration of substance $j$ at the inlet, $v_{j}$ is the rate of influent stream to the system (equal to effluent) and $r_{j}$ is the increase/decay rate of substance $j$ according to the reactions.

\subsubsection{Energy balance}

The solution of energy balance gives (COMSOL 4.3, 2013):

$$
V_{r} \sum_{j} c_{j} C_{p, j} \frac{d T}{d t}=Q_{r}+Q_{w}+\sum_{j} v_{j} c_{i, j}\left(h_{i, j}-h_{j}\right)
$$

where $h_{j}$ is the enthalpy of substance $j, C_{p, j}$ the heat capacity of substance $j, Q_{w}$ the amount of energy lost or gained through the reactor walls, and $Q_{r}$ the energy consumed or released by reactions,

$$
Q_{r}=V_{r} \sum_{k} H_{k} r_{k}
$$

57 with $H_{k}$ as the enthalpy of reaction $k . Q_{w}$ is calculated analytically for the cylindrical shape of reactor:

$$
Q_{w}=2 \pi L \lambda_{m}\left(T_{s}-T\right)
$$
inner surface of reactor wall calculated by

$$
T_{s}=\frac{\lambda_{m} T+\lambda_{w} T_{w}}{\lambda_{m}+\lambda_{w}}
$$




$$
\lambda_{m}=\frac{\kappa_{m}}{\ln \left(r_{s} / r_{i n}\right)}, \lambda_{w}=\frac{\kappa_{w}}{\ln \left(r_{o} / r_{s}\right)}
$$

where $r_{s}$ is the reactor inner radius, $r_{i n}$ is the radius of inlet, $r_{o}$ is the reactor outer radius, $\kappa_{w}$ is the thermal conductivity of the wall material and $\kappa_{m}$ is the overall thermal conductivity of the system calculated by $\kappa_{m}=\sum s_{j} \kappa_{j}$ where $\kappa_{j}$ is the thermal conductivity and $s_{j}$ is the saturation of substances inside the vessel calculated by $s_{j}=c_{j} \phi M_{j} / \rho_{j} . \phi$ is the porosity of vessel, $M_{j}$ is the molecular weight and $\rho_{j}$ is the density of substance $j$. The enthalpy of substances at different system temperatures are calculated as,

$$
h_{j}(T)=\int_{0}^{T} C_{p, j} d T+h_{j}(0)
$$

where $h_{j}(0)$ is the enthalpy of substance $j$ at a reference temperature and pressure. $h_{j}(0)$ values at $293 \mathrm{~K}$ and $13 \mathrm{MPa}$ for methane, $\mathrm{CO}_{2}$ and water were calculated $12.25,10.5$ and $1.72 \mathrm{kJmol}^{-1}$ respectively (NIST Chemistry WebBook, Linstrom and Mallard, 2013). $C_{p, j}$ was assumed constant for the $\mathrm{p} / \mathrm{T}$ conditions of experiments.

\subsubsection{Reactions}

The solution of mass and energy balance considers the following reactions inside the reactor. Depending on the $\mathrm{p} / \mathrm{T}$ conditions, hydrate dissolution and formation occur inside the hydrate stability region and hydrate dissociation occurs outside the hydrate stability region (see Fig. 1). The following pair of reversible reactions were considered under the stability conditions:

$$
\begin{aligned}
& \mathrm{CH}_{4} \cdot 6 \mathrm{H}_{2} \mathrm{O} \leftrightarrow \mathrm{CH}_{4 \text { (aqueous) }}+6 \mathrm{H}_{2} \mathrm{O} \\
& \mathrm{CO}_{2} \cdot 6 \mathrm{H}_{2} \mathrm{O} \leftrightarrow \mathrm{CO}_{2 \text { (aqueous) }}+6 \mathrm{H}_{2} \mathrm{O}
\end{aligned}
$$

Reactions $8 \mathrm{a}-8 \mathrm{~b}$ account for hydrate dissolution while thermodynamically stable, but undersaturated with respect to the gas in the solution (water). Hydrate precipitation (formation) occurs at over-saturated conditions. A set of irreversible reactions were considered for $\mathrm{p} / \mathrm{T}$ conditions at which hydrates are thermodynamically unstable, 


$$
\begin{aligned}
& \mathrm{CH}_{4} \cdot 6 \mathrm{H}_{2} \mathrm{O} \rightarrow \mathrm{CH}_{4(\text { aqueous })}+6 \mathrm{H}_{2} \mathrm{O} \\
& \mathrm{CO}_{2} \cdot 6 \mathrm{H}_{2} \mathrm{O} \rightarrow \mathrm{CO}_{2 \text { (aqueous })}+6 \mathrm{H}_{2} \mathrm{O}
\end{aligned}
$$

Reactions $9 \mathrm{a}$ and $9 \mathrm{~b}$ account for disintegration of hydrate when it is not stable. Since during the experiments the pressure of the system was kept constant, the stability of hydrates in model was determined only by the system temperature. The hydrate instability occurred when the system temperature exceeded the hydrate stability temperature $T_{c}$. For the experiments at $13 \mathrm{MPa}$, the stability temperatures for $\mathrm{CH}_{4}-/ \mathrm{CO}_{2}$-hydrate were measured from stability curves (Fig. 1) at $13.7 / 9.5{ }^{\circ} \mathrm{C}$, respectively. These values were lower for the experiment at $8 \mathrm{MPa}$ and were determined to be 8.95 and $8.9{ }^{\circ} \mathrm{C}$ for $\mathrm{CH}_{4^{-}}$and $\mathrm{CO}_{2}$ - hydrate, respectively.

According to Haeckel et al. (2004) the rate of hydrate dissolution/formation $r_{j}$ was calculated by,

$$
r_{j}= \begin{cases}k_{r e v, j}\left(c_{c t e, j}-c_{\text {Hydrate }_{j}}\right) & \text { if } T<T_{c}, \\ k_{i r r, j} & \text { if } T>T_{c} .\end{cases}
$$

Under hydrate stability condition, $k_{r e v, j}$ is defined based on the Arrhenius formula,

$$
k_{r e v, j}=A_{j} e^{-\frac{\Delta E_{j}}{R_{c} T}}
$$

where $T$ is the system temperature, $R_{c}$ is the universal gas constant, and for hydrate $j, A_{j}$ denotes the frequency factor and $\Delta E_{j}$ the activation energy (Table 1 ). $A_{j}$ is typically expressed in $\left[\mathrm{mol} \cdot \mathrm{m}^{-2} \cdot \mathrm{s}^{-1} \cdot \mathrm{Pa}^{-1}\right]$ and to convert its unit to $\left[\mathrm{s}^{-1}\right]$ the following equation is used (Kim et al., 1987):

$$
A_{j}\left[s^{-1}\right]=\frac{6 P_{\text {sys }}}{\Psi \rho_{j} d_{j}} A_{j}\left[\mathrm{molm}^{-2} \mathrm{~s}^{-1} \mathrm{~Pa}^{-1}\right]
$$

where $d_{j}$ is the average diameter of hydrate particles, $P_{s y s}$ is the system pressure, $\rho_{j}$ is the hydrate molar density, and $\Psi$ is the particles geometry term ( $\Psi=1$ for spherical particles). According to Haeckel et al. (2004), Eq. (10) assumes hydrate dissolution or formation to be proportional to the saturation of methane in pore water with respect to its equilibrium concentration $\left(c_{c t e}\right)$. At 
hydrate instability conditions (at system temperatures above the stability temperature) $k_{i r r, j}$ was assumed constant and treated as an adjustable parameter.

The exchange rate of methane and $\mathrm{CO}_{2}$ from pure phase to the water phase and vise-versa is defined by the following reversible reactions,

$$
\begin{aligned}
\mathrm{CO}_{2(\text { liquid })} & \leftrightarrow \mathrm{CO}_{2 \text { (aqueous) }} \\
\mathrm{CH}_{4(\text { gas })} & \leftrightarrow \mathrm{CH}_{4(\text { aqueous })}
\end{aligned}
$$

where the exchange rates follow the same mechanism as of Eq. (10) without the temperature dependencies, and similar to Noyes et al. (1996),

$$
r_{j}=k_{s, j}\left(c_{c t e, j}-c_{j}\right)
$$

The exchange rate constants $k_{s, j}$ are estimated by the fitting procedure. The values of $c_{c t e}$ for aqueous $\mathrm{CO}_{2}$ and methane, and both $\mathrm{CO}_{2-}$ and $\mathrm{CH}_{4}$-hydrates at experimental temperatures, pressures and salinity are calculated according to Henry's law and listed in Table 1.

\subsection{Optimization technique}

Interior-reflective Newton methods (Coleman and Li, 1996; Gharasoo et al., 2017) which are often employed in solving optimization problems have difficulties in minimizing this model due to high nonlinearity and discontinuity of the objective function. We thus used a hybrid response surface surrogate-based method which also reduces the computation costs of the optimization process. The details of the algorithm is presented in Babaei and Pan (2016) where the authors showed that the surrogate model that most consistently and robustly results in a computationally efficient optimization operation is the Radial Basis Function (RBF).

We first define normalized root-mean-square derivations (NRMSD) for inventory $\mathrm{CH}_{4}$ and $\mathrm{CO}_{2}$ as functions of four unknown parameters $k_{i r r, M G H}, k_{i r r, C G H}, k_{s, C H 4}$, and $k_{s, C O 2}$ : 


$$
\begin{aligned}
\mathrm{NRMSD}_{C O_{2}} & =\frac{\sqrt{\mathbf{E}\left(\left(C \mathrm{O}_{2}{ }^{\text {inv. }}\right)-\left(C \mathrm{O}_{2}{ }^{\text {inv.exp }}\right)\right)^{2}}}{\max \left(C \mathrm{O}_{2}{ }^{\text {inv.exp }}\right)-\min \left(C \mathrm{O}_{2}{ }^{\text {inv.exp }}\right)} \\
\mathrm{NRMSD}_{C H_{4}} & =\frac{\sqrt{\mathbf{E}\left(\left(C H_{4}{ }^{i n v .}\right)-\left(C H_{4}{ }^{\text {inv.exp }}\right)\right)^{2}}}{\max \left(C H_{4}{ }^{\text {inv.exp }}\right)-\min \left(C H_{4}^{\text {inv.exp }}\right)}
\end{aligned}
$$

where $\mathbf{E}$ is the mean square error function, $\mathrm{CO}_{2}{ }^{i n v}, \mathrm{CO}_{2}{ }^{\text {inv.exp }}, \mathrm{CH}_{4}{ }^{\text {inv. }}$, and $\mathrm{CH}_{4}{ }^{\text {inv.exp }}$ are respectively the inventory $\mathrm{CO}_{2}$ calculated from the numerical model, inventory $\mathrm{CO}_{2}$ calculated from experiment, inventory $\mathrm{CH}_{4}$ calculated from the numerical model and inventory $\mathrm{CH}_{4}$ calculated from experiment. The objective function to be minimized is written as

$$
\mathbf{f}\left(k_{i r r, M G H}, k_{i r r, C G H}, k_{s, C H 4}, k_{s, C O 2}\right)=\sum_{i=1}^{4}\left(\operatorname{NRMSD}_{C O_{2}}+\operatorname{NRMSD}_{C H_{4}}\right)
$$

$222 \quad$

(

S

$$
\begin{aligned}
& \mathrm{CO}_{2}{ }^{\text {inv. }}=\mathrm{CO}_{2 \text { (liquid) }}+\mathrm{CO}_{2(\text { aqueous })}+\mathrm{CO}_{2(\text { hydrate })} \\
& \mathrm{CH}_{4}{ }^{\text {inv. }}=\mathrm{CH}_{4(\text { gas })}+\mathrm{CH}_{4(\text { aqueous })}+\mathrm{CH}_{4 \text { (hydrate })}
\end{aligned}
$$

35 Note that methane cannot exist in liquid form in our experimental $\mathrm{p} / \mathrm{T}$ conditions. 


\subsection{Model implementation}

The model was implemented in COMSOL Multiphysics@ using its Reaction Engineering Module. Two modeling setups, a batch and a reactor, were employed and coupled together. The inert components (gas-hydrates and sand) were simulated by the batch model and the mobile substances (water, $\mathrm{CO}_{2}$ and methane) by the reactor model. The two modeling setups were linked together to ensure a correct mass and energy balance for the entire system. The chemical parameter values for hydrates and other components were taken from the literature or NIST Chemistry WebBook (Linstrom and Mallard, 2013), listed in Table 1.

To maintain the model numerical stability, any sudden change of the boundary conditions as well as shift of hydrate thermodynamics (from stable to instable and vice versa) at stability temperatures must be treated continuously. To that end, the $\mathrm{CO}_{2}$ injection intervals in model were smoothed using a second derivative smoothing technique (COMSOL 4.3, 2013; Vermolen et al., 2009). A rigorous method was also applied for the definition of the local reaction rates (Section 3.1.3) to ensure a smooth transition of hydrate reaction rates from stable towards unstable conditions.

The COMSOL code is converted to function $\mathrm{f}\left(k_{i r r, M G H}, k_{i r r, C G H}, k_{s, C H 4}\right.$ with state variables as inputs and via COMSOL-MATLAB LiveLink ${ }^{\text {TM }}$, optimization is carried out in MATLAB treating COMSOL as a black-box. We use MATSuMoTo toolbox in MATLAB to call RBF to construct surrogate model of COMSOL function (Müller and Piché, 2011; Müller, 2014) and speed up the optimization process.

\subsection{Simulated scenarios}

Four scenarios were simulated at the following pressure-temperature conditions where the experimental data are available (Deusner et al., 2012):

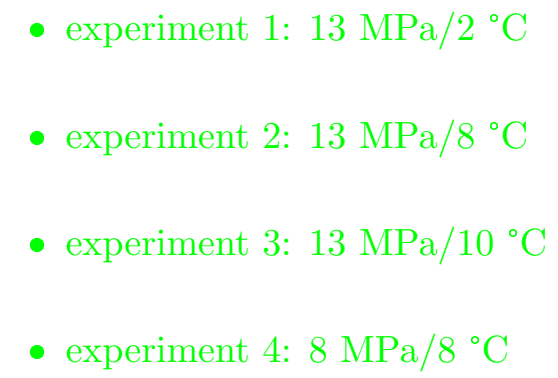


The phase diagram in Fig. 1 illustrates the experimental conditions with respect to the thermodynamic stability regimes of $\mathrm{CH}_{4^{-}}$and $\mathrm{CO}_{2}$-hydrate. The experiments were performed in a pressure vessel of $38 \mathrm{~cm}$ length, $8 \mathrm{~cm}$ cross section diameter, $18 \mathrm{~mm}$ casing thickness, with inlet (and outlet) of $13 \mathrm{~mm}$ diameter (Deusner et al., 2012).

The simulation developed to calibrate four experiments described above models a reactor with nearly two liters volume in which $95^{\circ} \mathrm{C} \mathrm{CO}_{2}$ was injected during multiple intervals separated with periods of equilibrium.

\section{Results and Discussion}

\subsection{Modeling results}

In the present study, the major modeling results of interest are the temporal changes of (1) the reactor's average temperature, (2) the overall methane and $\mathrm{CO}_{2}$ inventory, (3) the amount of methane- and $\mathrm{CO}_{2}$ - hydrate, and (4) the overall system thermal conductivity (Figs. 3 to 6). In the experiments, only the total amount of inventory methane and $\mathrm{CO}_{2}$ (including all pure, dissolved or hydrate phases) was calculated using outlet and inlet volume balancing. Therefore, the primary aim was to obtain a proper fit first with the methane inventory data and then with the $\mathrm{CO}_{2}$ inventory data, and then use the model to predict the fluctuations of temperature and gas-hydrate in the system. Since it was very difficult to directly record temperature values or determine the amount of gas-hydrates inside the pressure vessel, the use of model (after constraining the unknown parameters) helped to calculate these quantities that otherwise were unobtainable by means of laboratory equipments.

It is easy to approximately locate the start and the duration of injection intervals in Figs. 3 to 6 where abrupt temperature changes occurs. The system's highest temperatures are generally observed during the injection times when the average temperature of the system raised due to the entry of $95^{\circ} \mathrm{C} \mathrm{CO}_{2}$. In all experiments, the majority of methane-hydrate dissociation occurred during the injection intervals when the system's temperature increased above the hydrate stability temperature. Hence, the quicker the system reached or the longer it stayed at hydrate instability conditions, a higher amount of hydrate dissociation was obtained. In contrast, the accumulation or precipitation of hydrate mainly occurred during equilibration periods after the system lost heat to the surroundings. Further details and distinguishing features for 
every modeling scenario are separately addressed in the following sections.

\subsubsection{First scenario: $13 \mathrm{MPa} / 2{ }^{\circ} \mathrm{C}$}

The first experiment was performed at the lowest temperature leading to the lowest amount of methane-hydrate dissociation and the highest amount of $\mathrm{CO}_{2}$ accumulation. The experiment time was about 44 hours in which the $\mathrm{CO}_{2}$ was injected in four separate intervals. The maximum temperature reached only $285 \mathrm{~K}$ and was mainly achieved at the peak of injection intervals. Due to very low ambient temperature and high vessel pressure, the system hydrates were exposed to instability conditions only for a very short time. Most of the $\mathrm{CO}_{2}$ was, therefore, speculated to deposit in the vessel as $\mathrm{CO}_{2}$-hydrate with excess pore water. The modeling results also confirmed the accumulation of $\mathrm{CO}_{2}$-hydrate in the system. The qualitative model reproduction of the experiment data of the $\mathrm{CO}_{2}$ inventory supports this hypothesis and also suggests a homogeneous retention of the injected $\mathrm{CO}_{2}$ in the vessel (Fig. 3).

The long equilibration periods between the injection intervals allowed $\mathrm{CO}_{2}$ to slowly form $\mathrm{CO}_{2}$-hydrate and increased its retention yield. The model predicted the formation of nearly $3 \mathrm{~mol} \mathrm{CO}_{2}$-hydrate inside the vessel while the methane-hydrate dissociation was predicted to be less than 0.1 mol. A substantial formation of $\mathrm{CO}_{2}$-hydrate with the excess pore water was confirmed and was speculated as the main reason preventing rapid growth of preferential flow paths in this scenario.

\subsubsection{Second scenario: $13 \mathrm{MPa} / 8{ }^{\circ} \mathrm{C}$}

In comparison to the first experiment, the second experiment was done at a higher ambient temperature and therefore a significantly higher amount of methane-hydrate dissociation was observed (Fig. 4). While the length of experiment was marginally longer than the first experiment (about 45.5 hours), a higher amount of $\mathrm{CO}_{2}$ was injected through five intervals (25\% more $\mathrm{CO}_{2}$ was injected in comparison to the first experiment). The amount of heat transfered to the vessel was therefore higher but this was not the only feature contributing to a higher amount of methane-hydrate dissociation. In this scenario, the system was exposed to the hydrate instability conditions for a longer time thereby increasing the methane yield. Evidently, the small temperature difference between the experiment's initial condition and the hydrates instability zone derived the system to gas-hydrates instability conditions faster and led to the dissociation 
of a larger amount of methane-hydrate (the second highest amongst all experiments). The $\mathrm{CO}_{2}$ inventory was overestimated by the model. This suggests that the injected $\mathrm{CO}_{2}$ was possibly conveyed through preferential flow paths that were created due to methane-hydrate dissociation. Other factors such as consecutive injections, and a short equilibration time between the injection intervals, could also have enhanced the progression of the preferential flow paths in this experiment.

\subsubsection{Third scenario: $13 \mathrm{MPa} / 10{ }^{\circ} \mathrm{C}$}

The third experiment was done at the highest ambient temperature during which the $\mathrm{CO}_{2}$ hydrate was subjected to instability conditions for the entire duration of the experiment and therefore never formed. The modeled $\mathrm{CO}_{2}$ inventory curves deviated even more from the experimental data indicating once again the development of preferential flow paths prohibiting a spread of $\mathrm{CO}_{2}$ into the reactor volume. Comparing the results with the previous scenarios, it is speculated that the development of preferential flow paths are even stronger and that the formation of such pathways can be a function of ambient system temperature. Modeling results predicted a slightly higher dissociation of methane-hydrate than the second experiment while in the reality it was lower (Fig. 5). It is speculated that in the absence of $\mathrm{CO}_{2}$-hydrate formation, the injected $\mathrm{CO}_{2}$ at later stages followed the formerly generated pathways and discharged faster from the outlet. However, this was not the case for the second scenario where the slight formation of $\mathrm{CO}_{2}$-hydrate during the equilibrium intervals might have plugged the previously formed pathways, forcing the injected $\mathrm{CO}_{2}$ in the following stages to spread into the regions with high methane-hydrate concentration.

The modeling of this scenario revealed that the strongly developed and hydraulically connected preferential flow paths dramatically disturbed the uniform distribution of the heat that was introduced via the injection of supercritical $\mathrm{CO}_{2}$. Therefore, the interactions between the injected $\mathrm{CO}_{2}$ with the remaining methane-hydrate in the vessel was limited. Most of the heat at later injection intervals was, thus, expelled from the system and, despite the higher experimental ambient temperature, a lower rate of methane-hydrate dissociation was achieved.

The results show a clear dissimilarity between modeled and experimental data since the beginning and particularly after the consecutive first and second injection intervals. The quick progression of the preferential paths in this scenario may thus not only be related to the absence 
of $\mathrm{CO}_{2}$-hydrate formation but also may be favored by the consecutive injections at the beginning of the experiment. The total duration of this experiment was about 77 hours, the longest amongst all

\subsubsection{Forth scenario: $8 \mathrm{MPa} / 8^{\circ} \mathrm{C}$}

The fourth experiment (Fig. 6) was performed at a lower pressure compared to previous experiments. The ambient temperature as shown in Fig. 1 was slightly below the stability temperatures of both $\mathrm{CO}_{2^{-}}$and methane-hydrate and equal to that in the second scenario. The system thus easily reached hydrate instability conditions during the $\mathrm{CO}_{2}$ injection intervals. The highest amount of methane dissociation was achieved in this experiment given its total duration was longer (about 50\% longer) than the second experiment. The formation of preferential flow paths is evident as a result of $\mathrm{CO}_{2}$ inventory mismatch. The quick progress of preferential flow paths after the consecutive injections of $\mathrm{CO}_{2}$ at the second and third intervals is visible. As for the second experiment the formation of $\mathrm{CO}_{2}$-hydrate favored the distribution of the injected $\mathrm{CO}_{2}$ and enhanced the overall methane-hydrate dissociation in comparison with the third experiment. The experiment took roughly 71 hours to complete.

\subsection{Estimated kinetic parameters}

Most of the parameter values were taken from the literature, or calculated by SUGAR toolbox (Kossel et al., 2015) in close approximation with the previously reported values (see Table 1). The only unknown parameters that often vary between different systems were $k_{i r r, M G H}, k_{i r r, C G H}$ , $k_{s, C H 4}$, and $k_{s, C O 2}$. Using the above described optimization technique we obtained the following values for these parameters $k_{i r r, M G H}=0.02\left(\mathrm{~mol} \cdot \mathrm{m}^{-3} \mathrm{~s}^{-1}\right), k_{i r r, C G H}=0.03\left(\mathrm{~mol} \cdot \mathrm{m}^{-3} \mathrm{~s}^{-1}\right)$, $k_{s, C H 4}=4 \times 10^{-5}\left(\mathrm{~s}^{-1}\right)$, and $k_{s, C O 2}=1 \times 10^{-5}\left(\mathrm{~s}^{-1}\right)$. This values are in agreement with previously reported values. For instance, the values of $k_{s, C H 4}$ and $k_{s, C O 2}$ are in the same range of values reported in Noyes et al. (1996) for first-order gas-exchange rate constant. The estimated values for parameters describing hydrates dissociation at absolute instability conditions, $k_{i r r, M G H}$ and $k_{i r r, C G H}$, were about two orders of magnitude lower than the value reported in Jerbi et al. (2010) for $\mathrm{CO}_{2}$ dissociation. However, Jerbi et al. (2010) performed the experiments in a semi-batch stirred tank reactor at stirring velocity of $450 \mathrm{rpm}$. A simple comparison between the two systems (pressure vessel and stirred-tank reactor) shows that it is reasonable to obtain significantly 
lower dissociation rates in a pressure vessel.

We were able to obtain a convenient fit to methane inventory data for all the scenarios except the third one performed at $13 \mathrm{MPa} / 10{ }^{\circ} \mathrm{C}$. The fact that neither the model results for methane inventory nor the results for $\mathrm{CO}_{2}$ inventory of the third scenario were found to reasonably fit to the experimental data (Fig. 5) suggests that the underlaying processes in this experiment were too complicated to be described by the modeling approach presented. It is therefore difficult from this approach to correlate the rate of methane-hydrate dissociation in the third experiment with those in other scenarios. On the contrary, the model results did not fit properly to the $\mathrm{CO}_{2}$ inventory data at all. This might be mainly due to the development of preferential flow paths in the system causing the $\mathrm{CO}_{2}$ to poorly spread in the reactor volume and to leave the reactor early. Since the current model assumptions are based on perfect mixing, any deviation of model results from the $\mathrm{CO}_{2}$ inventory data can be linked to the occurrence of preferential flow paths and the heterogeneous transport of $\mathrm{CO}_{2}$ inside the vessel.

The aim was not, however, to obtain a perfect fit to each experiment with any combination of the values, but to find for each of these parameters a constant value to which a reasonable fit can be achieved to all the scenarios. It is worth noting that most of the parameters in reality might be a function of temperature, pressure and salinity. Since pressure was kept nearly constant in the vessel and the temperature of the system fluctuated within a narrow band, the majority of chemical properties including the estimated effective rates were assumed constant.

\subsection{Dissolution rate of methane and carbon dioxide in water}

A significant sensitivity of the model to the dissolution rates of methane and $\mathrm{CO}_{2}$ in water was found during the model analysis. It was displayed that not only the final aqueous concentrations, $c_{c t e, C H 4}$ and $c_{c t e, C O 2}$ (calculated from SUGAR toolbox (Kossel et al., 2015) and listed in Table 1), but also the exchange rate constants between water and gas, $k_{s, \mathrm{CH} 4}$ and $k_{s, \mathrm{CO} 2}$, are important for the dissociation/formation of the hydrate at the beginning of the experiments and after the injection intervals. Numerical stability of the model was found to be very sensitive to the values of these parameters. These parameters might be less influential at field-scale than in the experiments due to the comparatively larger computation time-scales or larger size of the domain. 


\subsection{The relation between carbon dioxide retention and methane release}

The present findings speculate that the differences between modeling and experimental results are associated with the presence of flow heterogeneities and their relative growth inside the vessel. Since model predictions are based on perfect mixing assumptions, the differences between model predictions and experimental data in $\mathrm{CO}_{2}$ inventory curves (Figs. 4 and 6) indicate that the injected $\mathrm{CO}_{2}$ bypassed the majority of the vessel contents in all scenarios except the first one. This, however, only hindered the methane-hydrate dissociations in the third experiment, suggesting that in both, the second and fourth scenarios the injected $\mathrm{CO}_{2}$ still managed to deliver its heat to the vessel contents.

The only major difference between other scenarios and the third scenario is the formation of $\mathrm{CO}_{2}$-hydrate, which appears to affect positively the dissociation of methane-hydrate in the second and the fourth scenarios. The reason may be related to the formation of solidified $\mathrm{CO}_{2}-$ hydrate clogging up the previously formed flow pathways, thereby forcing the upcoming $\mathrm{CO}_{2}$ to choose a different pathway. Alternatively, the lower enthalpy of formation of $\mathrm{CO}_{2}$-hydrate in comparison to methane-hydrate may have thermodynamically favored methane-hydrate dissociation. Either way, it appears that at $\mathrm{p} / \mathrm{T}$ conditions closer to the methane-hydrate instability zone, the retention of $\mathrm{CO}_{2}$ catalyzes the methane-hydrate dissociation. This might have the following practical implications for $\mathrm{CO}_{2}$ injection into hydrate reservoirs. First, the temperature of the injected $\mathrm{CO}_{2}$ can be adjusted in order to avoid the reservoir temperatures at which $\mathrm{CH}_{4}$-hydrate is stable and $\mathrm{CO}_{2}$-hydrate is unstable (at $\mathrm{p} / \mathrm{T}$ conditions similar to the third scenario). Secondly, altering the reservoir conditions to the $\mathrm{p} / \mathrm{T}$ conditions at which $\mathrm{CH}_{4}$-hydrate is unstable and $\mathrm{CO}_{2}$-hydrate is stable might increase both $\mathrm{CO}_{2}$ retention yield and $\mathrm{CH}_{4}$-hydrate dissociation. This might be only obtainable by combining the two techniques of depressurization and thermal stimulation together. Accordingly, it might be safe to say that injection of $\mathrm{CO}_{2}$ into the gas-hydrate reservoirs at $\mathrm{p} / \mathrm{T}$ conditions similar to the third scenario is not economically and environmentally favorable.

\subsection{Guidelines for field-scale modeling}

The dissociation of hydrate was not entirely related to the amount of heat that was introduced to the system but to the quality of heat distribution, information that is difficult to quantify empirically. The comparison between an ideally mixed model and experimental data allowed us to 
interpret the system behavior in each case based on the discrepancies observed. Methane-hydrate dissociation yield is likely related to the relative combination of several factors that cannot be imposed externally, such as reservoir temperature, pressure, salinity, structural heterogeneities, composition of sand layers, or the spatial distribution of these quantities. In turn, several factors can be regulated during the production from gas-hydrate deposits which were discovered to have a noteworthy influence on the final results. These include temperature of superheated $\mathrm{CO}_{2}$, the equilibration periods between injection intervals, and the injection strategy. The succession of injection intervals was shown detrimental to the whole process due to bolstering the preferential flow paths and thus decreasing the quality of heat expansion. The mismatches between model and experiments were mostly observed after the consecutive injections. The longer the equilibration intervals, the lesser was the extension of preferential pathways through the vessel. Low injection rates of $\mathrm{CO}_{2}$ were found to benefit the $\mathrm{CO}_{2}$ retention process through homogenizing the distribution of $\mathrm{CO}_{2}$, allowing it to disperse further into the depth of hydrate deposit while preventing the restoration of preferential flow paths. A similar finding has been recommended by White et al. (2011). It is also suspected that the formation of $\mathrm{CO}_{2}$-hydrate not only improved the quality of $\mathrm{CO}_{2}$ retention but also enhanced the overall methane-hydrate dissociation. Therefore, the method at $\mathrm{p} / \mathrm{T}$ conditions between the two hydrates stability curves (at conditions similar to the third experiment) was shown highly ineffective. However, more data are needed to prove that the $\mathrm{CO}_{2}-\mathrm{CH}_{4}$-hydrate conversion must be avoided at such $\mathrm{p} / \mathrm{T}$ conditions by performing more experiments at such conditions.

In addition, it was shown that the pore-scale heterogeneities that are typically ignored at field-scale models can immensely affect the simulation results. Since the inclusion of such smallscales effects into reservoir models is computationally very elaborate, the urge of upscaled models which are able to estimate the small-scale ( $\mathrm{cm}$ to meters) dynamics in the presence of heterogeneities as a function of system pressure and temperature is noted. These models can be either empirical or analytic.

\subsection{Model predictability and limitations}

It was shown that the model performs better at low temperatures and high pressures deep inside the hydrate stability zone (at conditions similar to the first experiment). However, the predictability of model reduced at higher temperatures, closer to hydrate instability zone (at 
conditions similar to the third experiment). The analysis of results shows that the presented model was able to forecast the behavior of a (semi-)homogenized system. A similar findings was noted by the Ignik Sikumi field trial (Schoderbek et al., 2013). The deviations between modeling results and experiments occurred when preferential flow paths played a major role on the transport of substances, and when the system become extremely heterogeneous.

\section{Conclusions and Implications}

We presented here the results of a kinetically-focused simulation which is used to explain the experimental results reported in Deusner et al. (2012) without extra complexities of fully spatiallyresolved, computationally-expensive fluid dynamics simulations. Unlike most of the studies in this field in which the focus has been given to the fluid dynamics and transport effects and as a result reaction kinetics were oversimplified, in this study a detailed definition of kinetics was employed. The transport phenomena, however, were simplified to a basic mass and energy balance for a representative elementary volume (2 liters) which is equal or smaller than the typical size of a grid block in continuum field-scale models. This study demonstrates the significance of reaction kinetics on the extraction of natural gas through the injection and exchange of $\mathrm{CO}_{2}$ with methane in gas-hydrates. The details of kinetics are therefore shown to be too significant to be easily discarded despite the fact that such simplifications are commonly observed in field-scale models. Furthermore, it is noted that an equal emphasis should be given to the details of smallscale heterogeneities in reservoir simulators in order to correctly model hydrate exploitation at field-scale. To avoid excessive computational demands of high-resolution models at field-scale while taking the effects of pore-scale heterogeneities into consideration, it is required to develop upscaled models that perform at small scales ( $\mathrm{cm}$ to $\mathrm{m}$ ). Such up-scaled models do not explicitly solve all the transport mechanisms in details, but describe and encapsulate the overall impact of small-scale heterogeneities into a relatively accurate and computationally-inexpensive box-model. With the help of the model we estimated the values of key intrinsic parameters that are unknown, and are different depending on the experimental setup employed. These parameters are usually difficult to directly quantify from the experiments and as a result often over or underestimated. 


\section{Acknowledgments}

This research was funded by the German Ministry of Economy (BMWi) through the SUGAR project (grant No. 03SX320A). M.G. acknowledges the funding from the European Research Council (ERC Grant Agreement No. 616861 - MicroDegrade). The authors thank the following individuals: Henrik Ekström (COMSOL Inc.) for his valuable suggestions and help in development of the model, Andrew Dale (Geomar) for the proof reading of the text, and Christian Deusner (Geomar) for sharing the experimental data.

\section{References}

Ahmadi, G., Ji, C., Smith, D. H., 2007. Production of natural gas from methane hydrate by a constant downhole pressure well. Energy Convers Manage 48(7), 2053-2068.

Archer, D., Buffett, B., Brovkin, V., 2009. Ocean methane hydrates as a slow tipping point in the global carbon cycle. Proc. Natl. Acad. Sci. USA 106(49), 20596-20601.

Babaei, M., Pan, I., 2016. Performance comparison of several response surface surrogate models and ensemble methods for water injection optimization under uncertainty. Comput Geosci 91 (Supplement C), 19-32.

Burwicz, E., Rüpke, L., Wallmann, K., 2011. Estimation of the global amount of submarine gas hydrates formed via microbial methane formation based on numerical reaction-transport modeling and a novel parameterization of holocene sedimentation. Geochim Cosmochim Acta 75(16), 4562-4576.

Clarke, M. A., Bishnoi, P., 2004. Determination of the intrinsic rate constant and activation energy of CO2 gas hydrate decomposition using in-situ particle size analysis. Chem Eng Sci 59(14), 2983-2993.

Clarke, M. A., Bishnoi, P., 2005. Determination of the intrinsic kinetics of CO2 gas hydrate formation using in situ particle size analysis. Chem Eng Sci 60(3), 695-709.

Clarke, M. A., Bishnoi, P. R., 2001. Measuring and modelling the rate of decomposition of gas hydrates formed from mixtures of methane and ethane. Chem Eng Sci 56(16), 4715-4724.

Coleman, T. F., Li, Y., 1996. An interior trust region approach for nonlinear minimization subject to bounds. SIAM J Optim $6(2), 418-445$.

COMSOL 4.3, 2013. COMSOL Multiphysics Reference Guide (Version 4.3). COMSOL AB.

Dashti, H., Yew, L. Z., Lou, X., 2015. Recent advances in gas hydrate-based CO2 capture. J Nat Gas Sci Eng 23, $195-207$.

Deusner, C., Bigalke, N., Kossel, E., Haeckel, M., 2012. Methane production from gas hydrate deposits through injection of supercritical CO2. Energies 5(7), 2112-2140.

Ebinuma, T., 1993. Method for dumping and disposing of carbon dioxide gas and apparatus therefore. U.S. Patent, 5261490.

Englezos, P., Kalogerakis, N., Dholabhai, P., Bishnoi, P., 1987. Kinetics of gas hydrate formation from mixtures of methane and ethane. Chem Eng Sci 42 (11), 2659-2666.

Erfani, A., Fallah-Jokandan, E., Varaminian, F., 2017. Effects of non-ionic surfactants on formation kinetics of structure $\mathrm{h}$ hydrate regarding transportation and storage of natural gas. J Nat Gas Sci Eng 37, 397-408.

Fitzgerald, G. C., Castaldi, M. J., 2013. Thermal stimulation based methane production from hydrate bearing quartz sediment. Ind Eng Chem Res 52(19), 6571-6581.

Freer, E. M., Selim, M. S., Dendy Sloan Jr., E., 2001. Methane hydrate film growth kinetics. Fluid Phase Equilib. 185 (1-2), 65-75, proceedings of the 14 th symposium on thermophysical properties.

Gharasoo, M., Thullner, M., Elsner, M., 2017. Introduction of a new platform for parameter estimation of kinetically complex environmental systems. Environ Model Softw 98, 12-20.

Goel, N., 2006. In situ methane hydrate dissociation with carbon dioxide sequestration: Current knowledge and issues. J Pet Sci Eng 51, $169-184$. 
Haeckel, M., Suess, E., Wallmann, K., Rickert, D., 2004. Rising methane gas bubbles form massive hydrate layers at the seafloor. Geochim Cosmochim Acta 68(21), 4335-4345.

Handa, Y., 1986. Compositions, enthalpies of dissociation, and heat capacities in the range 85 to $270 \mathrm{~K}$ for clathrate hydrates of methane, ethane, and propane, and enthalpy of dissociation of isobutane hydrate, as determined by a heatflow calorimeter. J Chem Thermodyn 18(10), 915-921.

Jerbi, S., Delahaye, A., Fournaison, L., Haberschill, P., 2010. Characterization of CO2 hydrate formation and dissociation kinetics in a flow loop. Int J Refrig 33 (8), 1625-1631.

Jung, J. W., Espinoza, D. N., Santamarina, J. C., 2010. Properties and phenomena relevant to CH4-CO2 replacement in hydrate-bearing sediments. J Geophys Res: Solid Earth 115.

Kim, H., Bishnoi, P., Heidemann, R., Rizvi, S., 1987. Kinetics of methane hydrate decomposition. Chem Eng Sci 42(7), $1645-1653$

Koh, C. A., Sloan, E. D., Sum, A. K., Wu, D. T., 2011. Fundamentals and applications of gas hydrates. Annu Rev Chem Biomol Eng 2, 237-57.

Kossel, E., Bigalke, N., Pin̄ero, E., Haeckel, M., 2015. The SUGAR Toolbox - version 7.

Kvamme, B., Graue, A., Buanes, T., Kuznetsova, T., Ersland, G., 2007. Storage of CO2 in natural gas hydrate reservoirs and the effect of hydrate as an extra sealing in cold aquifers. Int J Greenh Gas Control 1 (2), 236-246.

Kvamme, B., Kuznetsova, T., Sapate, A., Qorbani, K., 2016. Thermodynamic implications of adding N2 to CO2 for production of CH4 from hydrates. J Nat Gas Sci Eng 35, 1594-1608, gas Hydrates and Applications.

Linstrom, P., Mallard, W., 2013. NIST Chemistry WebBook, NIST Standard Reference Database Number 69. National Institute of Standards and Technology, Gaithersburg MD, 20899.

Makogon, Y. F., 2010. Natural gas hydrates - A promising source of energy. J Nat Gas Sci Eng 2(1), $49-59$

Masoudi, R., Tohidi, B., 2005. Estimating the hydrate stability zone in the presence of salts and/or organic inhibitors using water partial pressure. J Pet Sci Eng 46, 23-36.

Moridis, G., Reagan, M. T., 2011a. Estimating the upper limit of gas production from class 2 hydrate accumulations in the permafrost: 1. Concepts, system description, and the production base case. J Pet Sci Eng 76, 194-204.

Moridis, G. J., Reagan, M. T., 2011b. Estimating the upper limit of gas production from class 2 hydrate accumulations in the permafrost: 2. Alternative well designs and sensitivity analysis. J Pet Sci Eng 76, 124-137.

Müller, J., 2014. Matsumoto: The matlab surrogate model toolbox for computationally expensive black-box global optimization problems. arXiv preprint arXiv:1404.4261.

Müller, J., Piché, R., 2011. Mixture surrogate models based on dempster-shafer theory for global optimization problems. Journal of Global Optimization 51 (1), 79-104.

Noyes, R. M., Rubin, M. B., Bowers, P. G., 1996. Transport of carbon dioxide between the gas phase and water under well stirred conditions: Rate constants and mass accommodation coefficients. J Phys Chem 100 (10), 4167-72.

Ohgaki, K., Takano, K., Sangawa, H., Matsubara, T., Nakano, S., 1996. Methane exploitation by carbon dioxide from gas hydrates-phase equilibria for CO2-CH4 mixed hydrate system. J Chem Eng Jpn 29(3), 478-483.

Ota, M., Abe, Y., Watanabe, M., Jr., R. L. S., Inomata, H., 2005. Methane recovery from methane hydrate using pressurized CO2. Fluid Phase Equilib 228-229, 553-559.

Pin̄ero, E., Marquardt, M., Hensen, C., Haeckel, M., Wallmann, K., 2013. Estimation of the global inventory of methane hydrates in marine sediments using transfer functions. Biogeosciences 10(2), 959-975.

Schoderbek, D., Farrell, H., Hester, K., Howard, J., Raterman, K., Silpngarmlert, S., Martin, K., Smith, B., Klein, P., 2013. ConocoPhillips gas hydrate production test final technical report. United States Department of Energy, 204.

Sultan, N., Cochonat, P., Foucher, J.-P., Mienert, J., 2004. Effect of gas hydrates melting on seafloor slope instability. Mar Geol 213, 379-401.

Tarnawski, V., Momose, T., Leong, W., 2011. Thermal conductivity of standard sands II. saturated conditions. Int J Thermophys 32(5), 984-1005.

Vafaei, M., Kvamme, B., Chejara, A., Jemai, K., 2014. A new reservoir simulator for studying hydrate dynamics in reservoir. Int J Greenh Gas Control 23, 12-21.

Vermolen, F. J., Gharasoo, M. G., Zitha, P. L. J., Bruining, J., 2009. Numerical Solutions of Some Diffuse Interface Problems: The Cahn-Hilliard Equation and the Model of Thomas and Windle. Int J Mult Comp Eng 7, 523-543. 
Voronov, V., Gorodetskii, E., Muratov, A., 2014. Study of methane replacement in hydrates by carbon dioxide in a cyclic process. J Nat Gas Sci Eng 21, 1107-12.

Waite, W. F., Santamarina, J. C., Cortes, D. D., Dugan, B., Espinoza, D. N., Germaine, J., Jang, J., Jung, J. W., Kneafsey, T. J., Shin, H., Soga, K., Winters, W. J., Yun, T. S., 2009. Physical properties of hydrate-bearing sediments. Rev Geophys 47(4).

Waite, W. F., Stern, L. A., Kirby, S. H., Winters, W. J., Mason, D. H., 2007. Simultaneous determination of thermal conductivity, thermal diffusivity and specific heat in sI methane hydrate. Geophys J Int 169(2), 767-774.

Wallmann, K., Pin̄ero, E., Burwicz, E., Haeckel, M., Hensen, C., Dale, A., Ruepke, L., 2012. The global inventory of methane hydrate in marine sediments: A theoretical approach. Energies 5(7), 2449-98.

White, M., Wurstner, S., McGrail, B., 2011. Numerical studies of methane production from class 1 gas hydrate accumulations enhanced with carbon dioxide injection. Mar Pet Geol 28(2), 546 - 560.

Yonkofski, C. M., Horner, J. A., White, M. D., 2016. Experimental and numerical investigation of hydrate-guest molecule exchange kinetics. J Nat Gas Sci Eng 35, 1480-89.

\section{Tables}



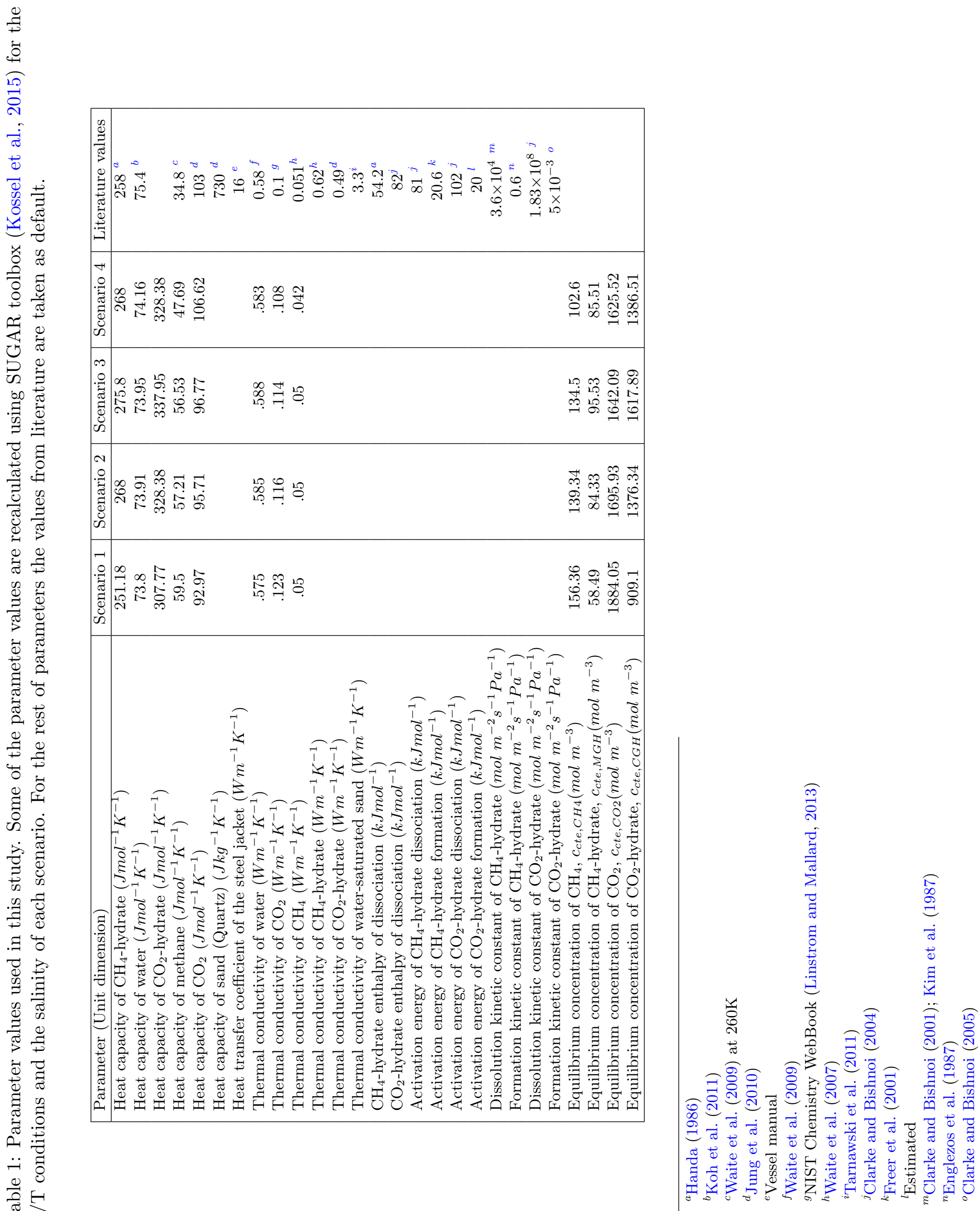


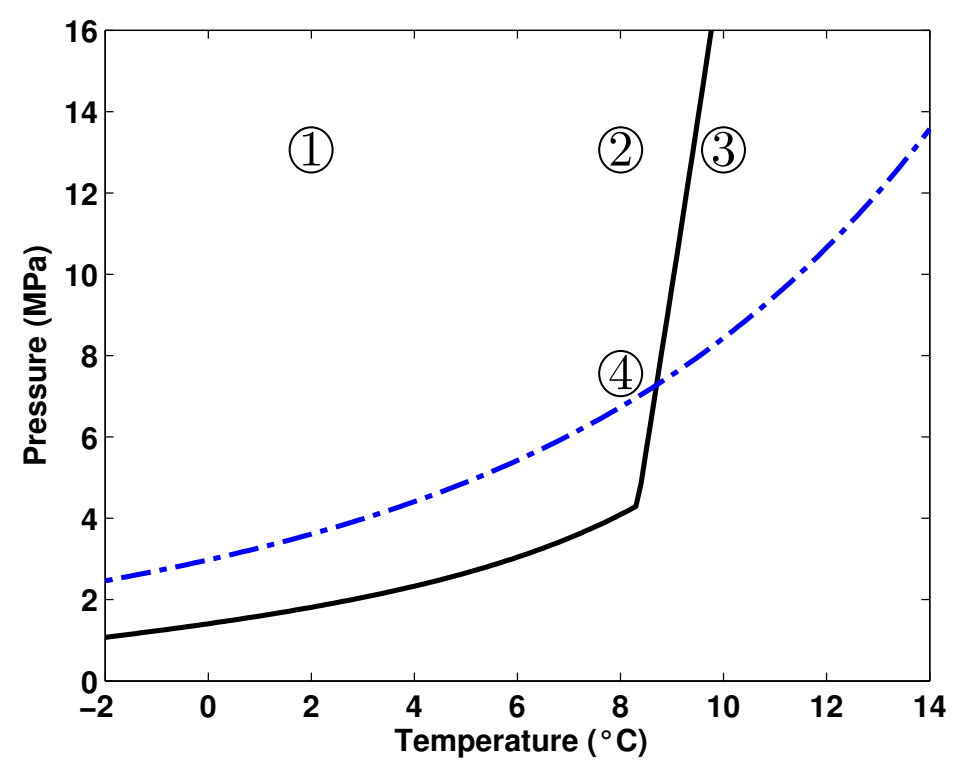

Figure 1: Stability curves for methane-hydrate (blue dotted line) and $\mathrm{CO}_{2}$-hydrate (black solid line) in respect to system pressure and temperature. At high pressures and low temperatures inside the stability zone hydrate dissolutes/forms according to Reactions 8a and 8b. Outside the hydrate stability zones at high temperatures and low pressures hydrate only dissociates (Reactions $9 \mathrm{a}$ and $9 \mathrm{~b}$ ). The encircled numbers indicate the pressure and temperature conditions at which the experiments were performed.

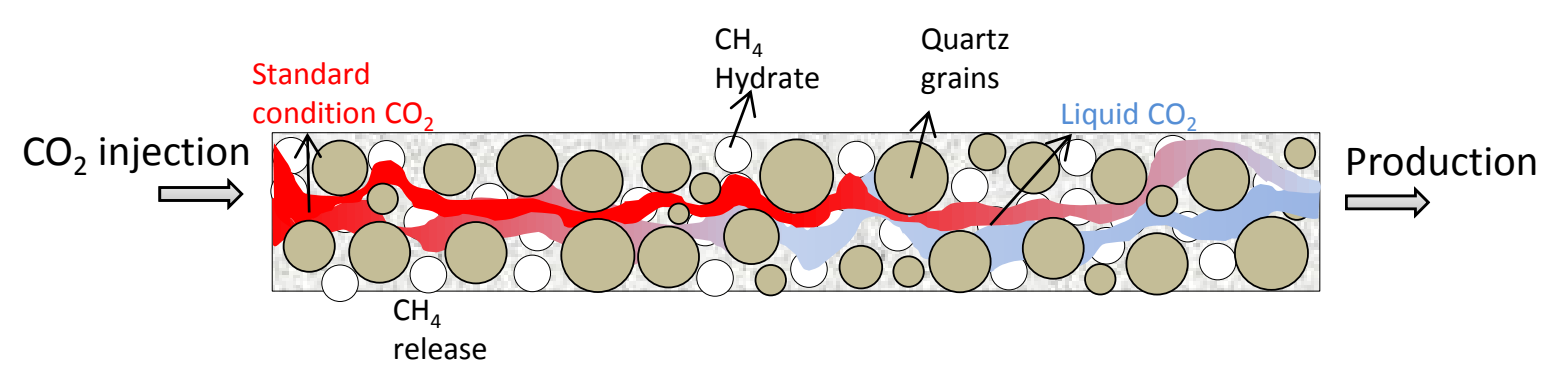

Figure 2: The schematic diagram of the processes occurring during supercritical $\mathrm{CO}_{2}$ injection into the pressure vessel containing $\mathrm{CH}_{4}$-hydrate and sand. 

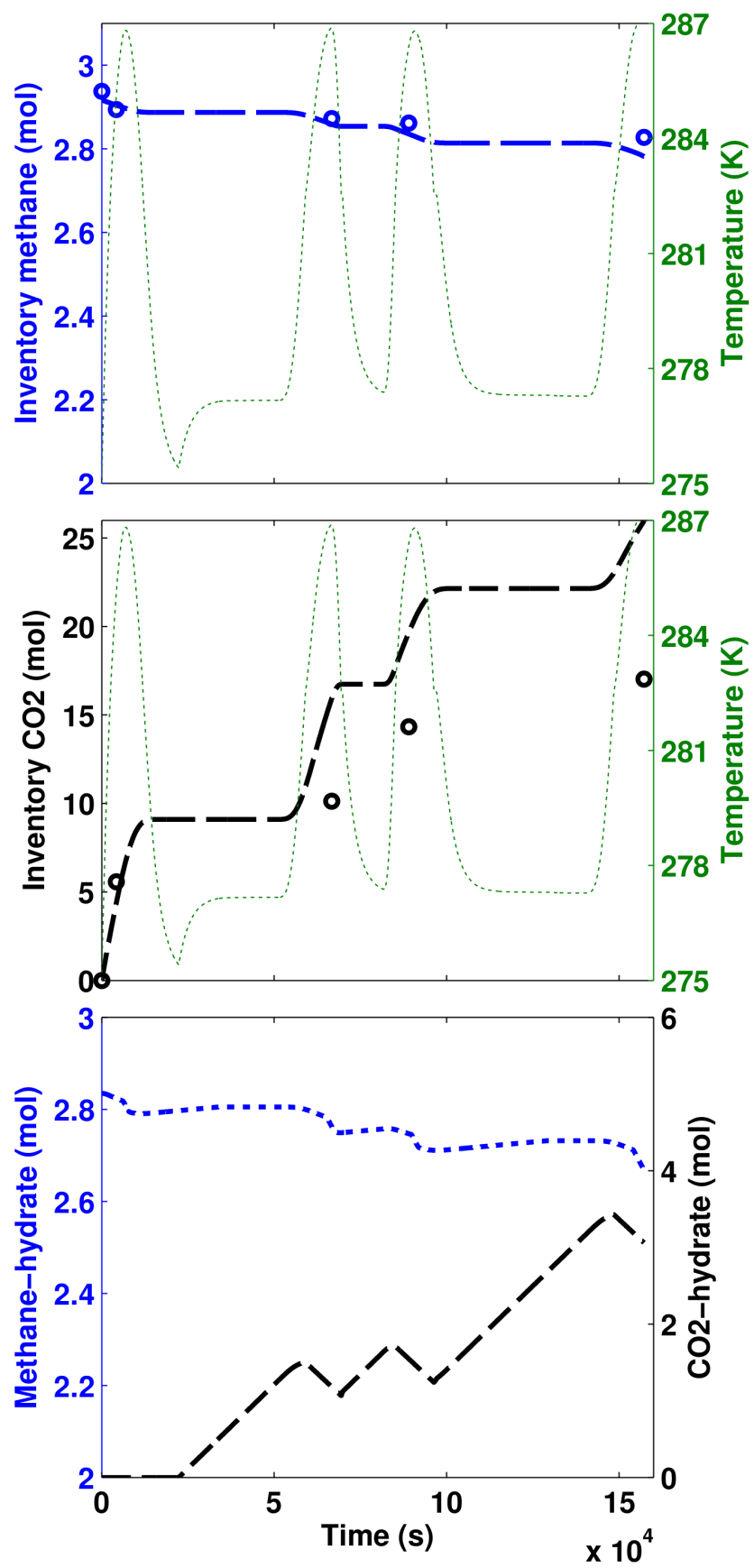

Figure 3: The modeling results of first scenario are shown by dashed lines and open dots are the reported experimental data for the $\mathrm{p} / \mathrm{T}$ conditions of $13 \mathrm{MPa}$ and $2^{\circ} \mathrm{C}$. 


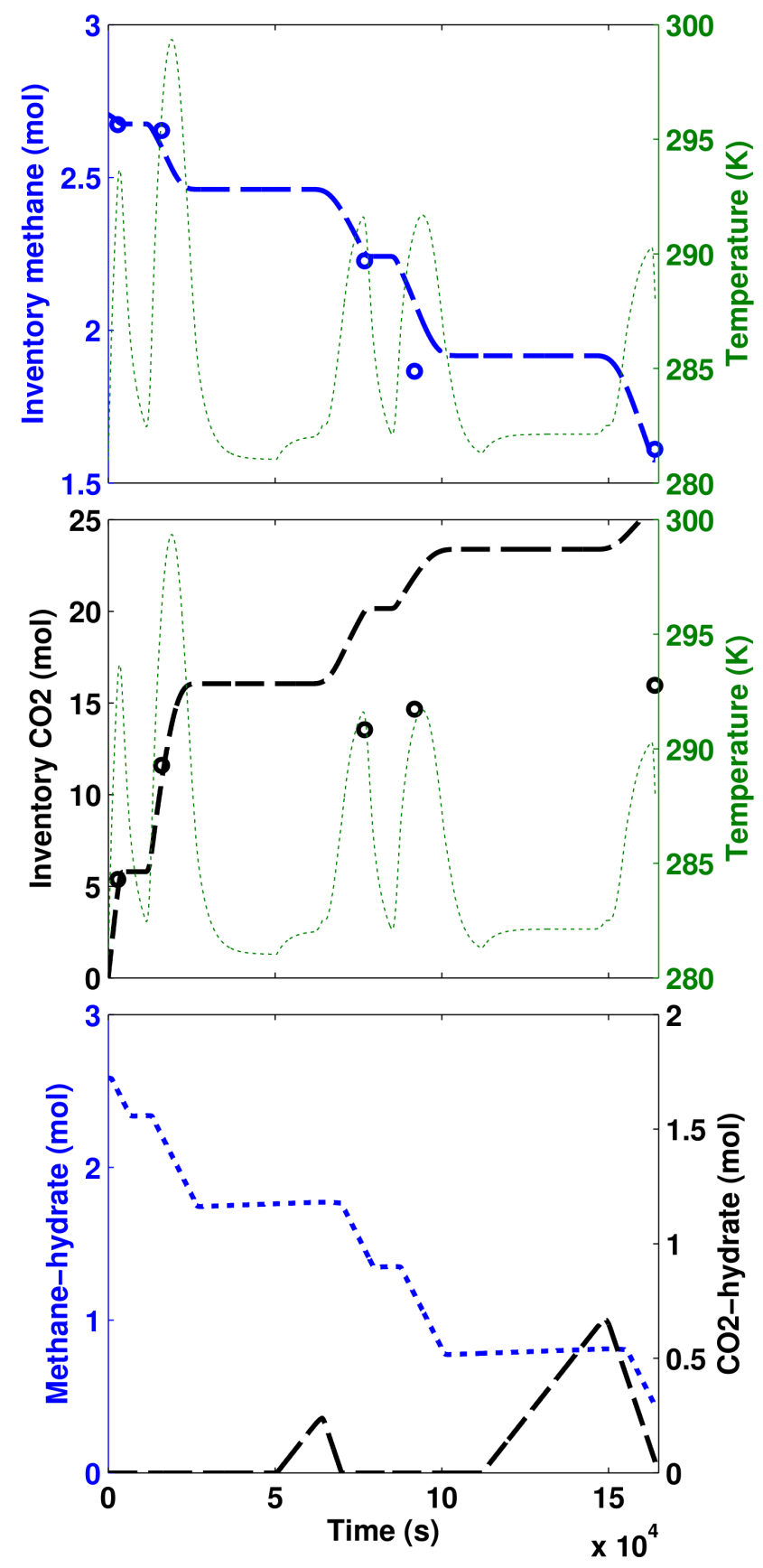

Figure 4: The modeling results of second scenario are shown by dashed lines and open dots are the reported experimental data for the $\mathrm{p} / \mathrm{T}$ conditions of $13 \mathrm{MPa}$ and $8^{\circ} \mathrm{C}$. 


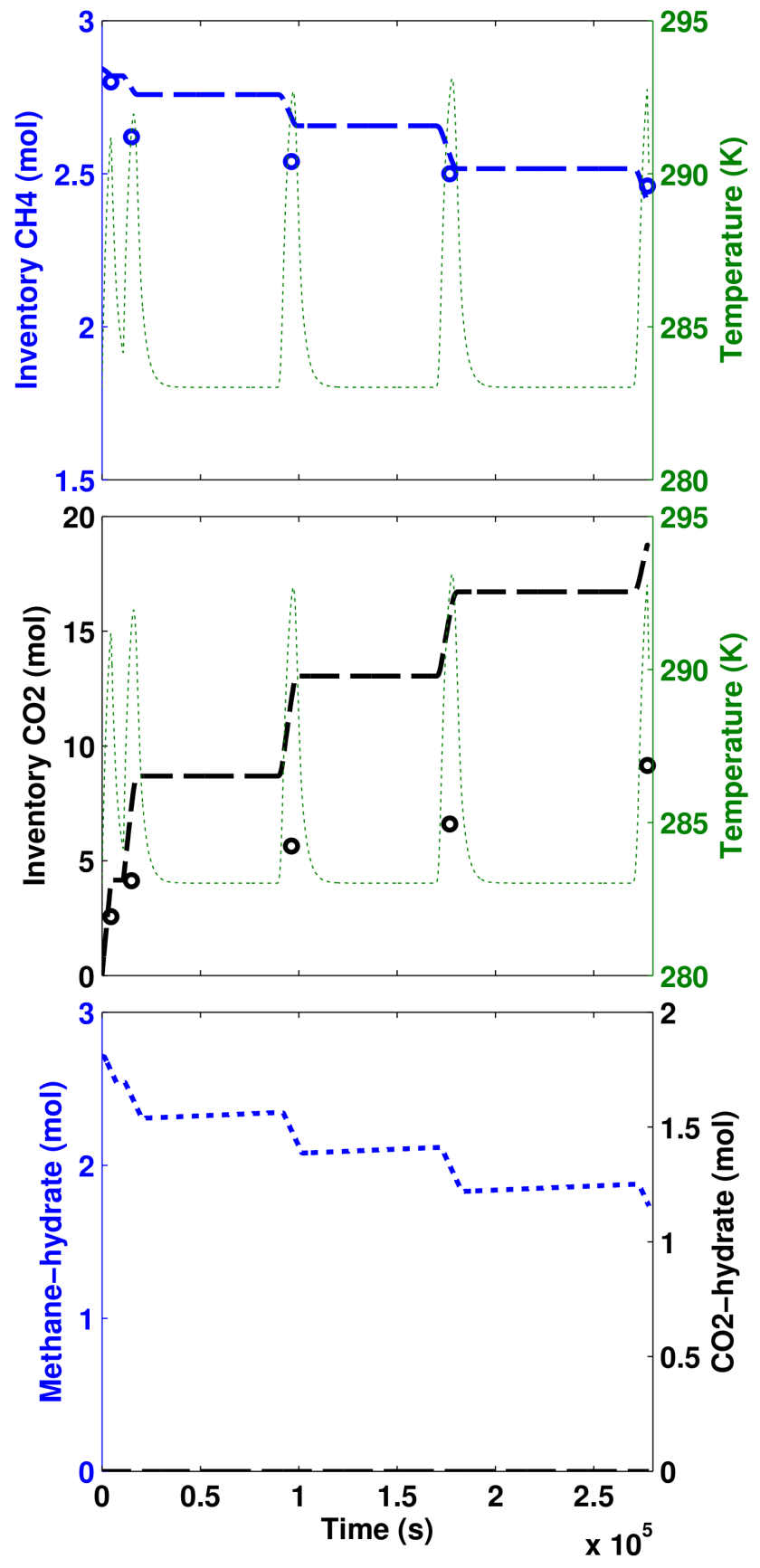

Figure 5: The modeling results of third scenario are shown by dashed lines and open dots are the reported experimental data for the $\mathrm{p} / \mathrm{T}$ conditions of $13 \mathrm{MPa}$ and $10^{\circ} \mathrm{C}$. 


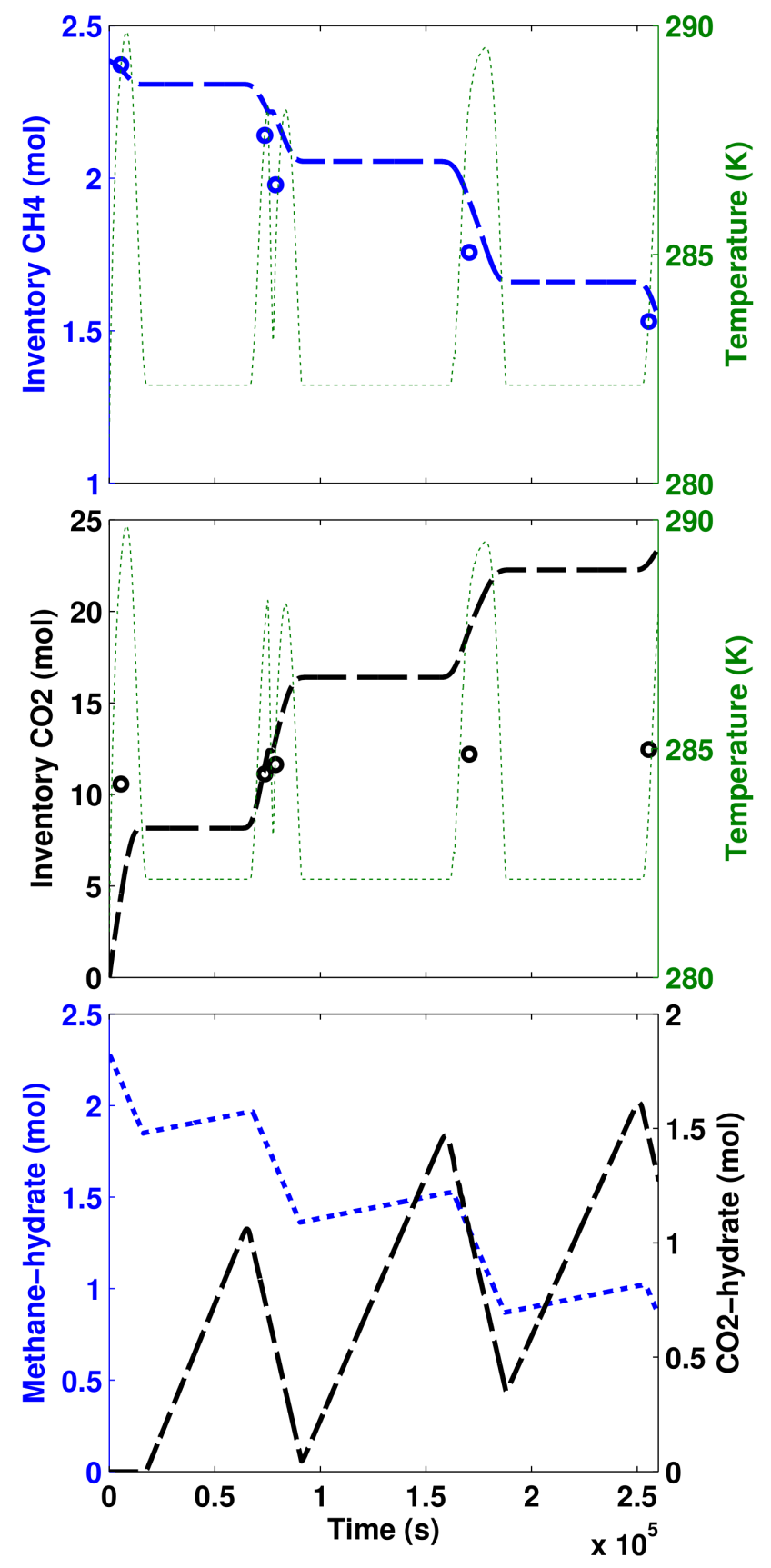

Figure 6: The modeling results of forth scenario are shown by dashed lines and open dots are the reported experimental data for the $\mathrm{p} / \mathrm{T}$ conditions of $8 \mathrm{MPa}$ and $8^{\circ} \mathrm{C}$. 